Clim. Past, 6, 1-17, 2010

www.clim-past.net/6/1/2010/

(C) Author(s) 2010. This work is distributed under

the Creative Commons Attribution 3.0 License.

\title{
A unified proxy for ENSO and PDO variability since 1650
}

\author{
S. McGregor, A. Timmermann, and O. Timm \\ IPRC, SOEST, University of Hawaii at Manoa, Hawaii, USA
}

Received: 24 August 2009 - Published in Clim. Past Discuss.: 23 September 2009

Revised: 1 December 2009 - Accepted: 6 December 2009 - Published: 5 January 2010

\begin{abstract}
In this manuscript we have attempted to consolidate the common signal in previously defined proxy reconstructions of the El Niño-Southern Oscillation into one individual proxy titled the Unified ENSO Proxy (UEP). While correlating well with the majority of input reconstructions, the UEP provides better representation of observed indices of ENSO, discrete ENSO events and documented historical chronologies of ENSO than any of these input ENSO reconstructions. Further to this, the UEP also provides a means to reconstruct the PDO/IPO multi-decadal variability of the Pacific Ocean as the low-pass filtered UEP displays multidecadal variability that is consistent with the 20th century variability of the PDO and IPO. The UEP is then used to describe changes in ENSO variability which have occurred since 1650 focusing on changes in ENSOs variance, multiyear ENSO events, PDO-like multi-decadal variability and the effects of volcanic and solar forcing on ENSO. We find that multi-year El Niño events similar to the 1990-1995 event have occurred several times over the last $31 / 2$ centuries. Consistent with earlier studies we find that volcanic forcing can induce a statistically significant change in the mean state of ENSO in the year of the eruption and a doubling of the probability of an El Niño (La Niña) event occurring in the year of (three years after) the eruption.
\end{abstract}

\section{Introduction}

The El Niño-Southern Oscillation (ENSO) is a coupled tropical Pacific ocean-atmosphere phenomenon which is the most dominant global source of interannual climate variability. ENSO is an oscillation characterized by marked changes in eastern equatorial Pacific sea surface temperature (SST),

Correspondence to: S. McGregor

(shaynemc@ hawaii.edu) known as El Niño, and a related large scale seesaw in atmospheric sea level pressure between the Australia-Indonesian region and the south-central tropical Pacific known as the Southern Oscillation. ENSO influences extreme weather events such as drought, flooding, bushfires and tropical cyclone activity across vast regions of the globe (Chan, 1985; Nicholls, 1985; Power et al., 1999). While the importance of its climatic impacts are relatively well known, many characteristics of the long term changes in ENSO frequency, magnitude and duration remain unknown. Further to this, whether ENSO variability has changed due to the already observed anthropogenically-induced climate change and how future projected changes will further influence ENSO are largely unresolved questions (Federov and Philander, 2000; van Oldenborgh et al., 2005; Merryfield, 2006).

For example, over the last few decades ENSO variability has appeared to shift toward a more El Niño-like state (Federov and Philander, 2000) where the 1980s and 1990s contained the two largest observed El Niño events on record along with a prolonged El Niño-like warming in the tropical Pacific Ocean that persisted for approximately 5-yrs in the early 1990s. Many studies have tried to ascertain the cause of these unusual events focusing on the roles of anthropogenically-induced climate change and natural decadal or ENSO variability (Latif et al., 1997; Power and Smith, 2007). At this stage it can not be ruled out with confidence that the recent changes of ENSO variability are a manifestation of natural variability (Timmermann, 1999).

However, a major difficulty in separating the anthropogenic signal from natural variability of the climate system is that the instrumental record covers a period of less than 150 years which is much too brief to properly address this fundamental question. Ideally to accurately ascertain the roles of natural and anthropogenically-induced variability of ENSO, hundreds to possibly even thousands of years of SST records are needed. As such, multi-century paleo climate reconstructions derived from annually resolved tree-ring, ice-core and

Published by Copernicus Publications on behalf of the European Geosciences Union. 

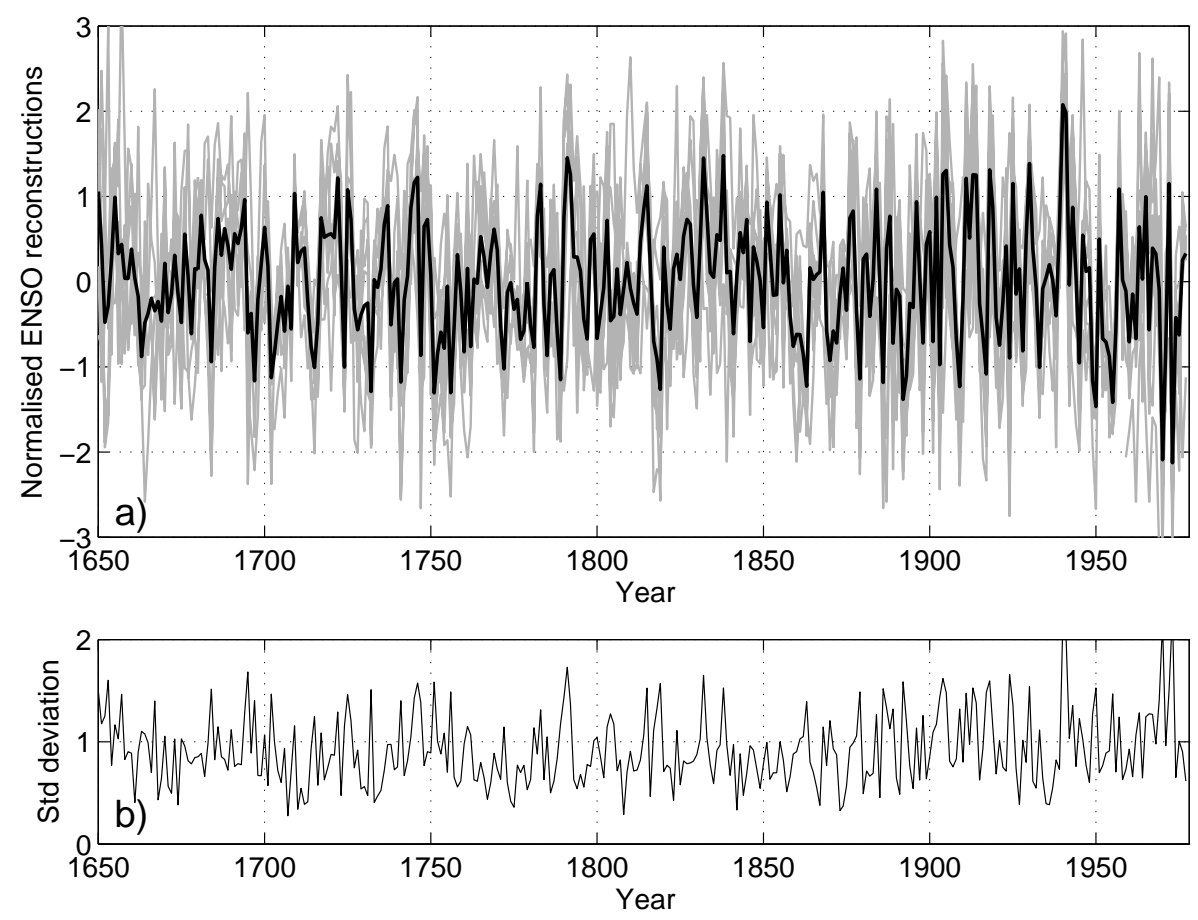

Fig. 1. Time series of (a) the 10 reconstructions (Table 1) of ENSO variability (gray) and the mean of these reconstructions (black). (b) Standard deviation of the 10 reconstructions.

coral records stand as the only way to assess the long term variability of ENSO.

There are currently numerous well crafted reconstructions of ENSO variability which all use a variety of current and paleo proxy data sources and a variety of methods to derive the indices (see discussion in Sect. 2) (Dunbar et al., 1994; Stahle et al., 1998; Cook, 2000; Mann et al., 2000; Evans et al., 2001, 2002; Cobb et al., 2003; Cook et al., 2008; Braganza et al., 2009). Each of these individual reconstructions correlates reasonably well with observations of ENSO variations during the instrumental period. However, while all represent the same signal there is a great deal of variability amongst the proxies (Fig. 1) which acts to reduce confidence in the individual proxies. For example, when looking at the normalized time series of 10 commonly used ENSO proxies (Dunbar et al., 1994; Stahle et al., 1998; Cook, 2000; Mann et al., 2000; Evans et al., 2001, 2002; Cobb et al., 2003; Cook et al., 2008; Braganza et al., 2009), we find that the standard deviation between the proxies at each time step is almost as large as the standard deviation of each index (Fig. 1). This variability amongst the proxy ENSO signals could represent an un-ENSO related climatic signal, an underlying biological signal, inaccurate proxy dating, or even ENSO itself. Every ENSO event is different and each event creates a slightly different spatial teleconnection pattern (Trenberth and Stepaniak, 2001). Therefore proxies derived from different regions could be expected to have slightly different signals of ENSO variability.
Here we attempt to consolidate the information contained in these 10 ENSO reconstructions to come up with a unified ENSO proxy (UEP) that captures the joint features of these reconstructions. This paper is organized as follows. Sect. 2 provides a description of the ENSO proxies used to derive the UEP in this study. Section 3 details the methods used to derive the UEP, while in section 4 the new ENSO proxy is validated against observations and historical documentary chronologies of ENSO. In section 5 we then discuss the variability of ENSO since 1650 and try to put into context the variability of the 20th century. A discussion and conclusions from the study are then presented in Sect. 6.

\section{ENSO proxy data}

The criteria used for the selection of proxy records used in this study were that they needed to (i) have at least annual resolution, (ii) extend back until at least the year 1800, and (iii) either be described in the literature as representing ENSO variability or be located in ENSO's prime center of action, the eastern-central tropical Pacific. Using these criteria we found 10 different proxies of ENSO variability. They are the proxies of Dunbar et al. (1994); Stahle et al. (1998); Cook (2000); Mann et al. (2000); Evans et al. (2001, 2002); Cobb et al. (2003); Cook et al. (2008); Braganza et al. (2009) (see Table 1). 


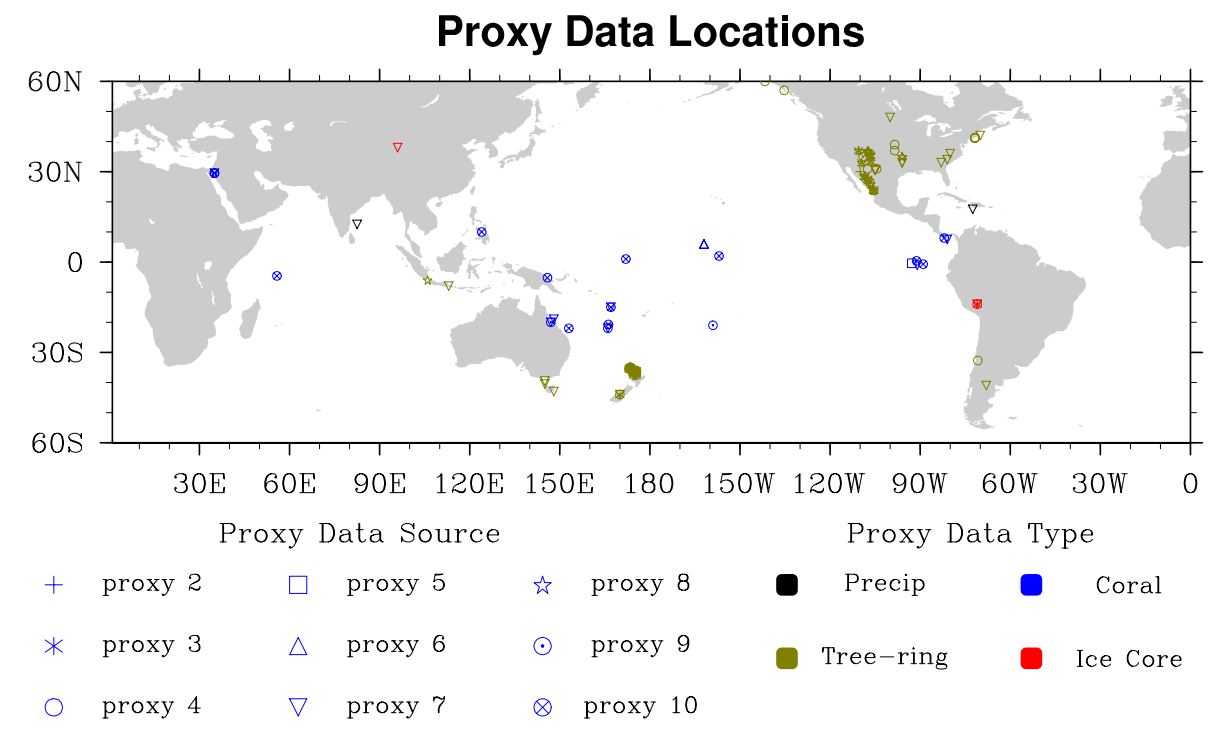

Fig. 2. The location and type of source proxy used in 9 of the 10 original ENSO proxies. See Table 1 for identification the proxy reconstruction corresponding to the proxy number displayed here.

Each of these ENSO proxies uses a variety of input data sources and methods to derive their representation of past ENSO variability. For example, when considering the proxy records used as inputs for these 10 proxies, at one end of the spectrum we have the proxy records of Dunbar et al. (1994) and Cobb et al. (2003) which both source data from corals based in a single region which is directly influenced by ENSO. Whereas, at the other end of the spectrum we have studies like that of Mann et al. (2000) who use a multiproxy network of diverse proxy indicators located in tropicalsubtropical regions that are influenced directly by ENSO or through its teleconnections. It is just as diverse when considering the methods used to derive these proxies from the original input proxy network. For example, the studies which only include data from one specific source region generally just splice each of the individual records together (Cobb et al., 2003). Whilst studies that use a multi-proxy network generally use a mathematical analysis technique (such as a Principal Component Analysis) to either, identify the common signal within the input proxy network (Braganza et al., 2009), or to decompose the observed data into their dominant spatiotemporal eigenmodes (Mann et al., 2000; Evans et al., 2002). In the latter case, the proxy data are then regressed against the associated times series of the leading eigenmodes during an overlapping period. In such way the regressed proxy data time series and the associated eigenvectors provide an estimate the spatiotemporal variability prior to the observational period.

The data redundancy across the 10 input networks used for the generation of these proxies is relatively small. For instance, there were 155 proxies used in total in the 9 of the 10 input networks and of these, less than $1 / 4$ were used in
Table 1. ENSO proxies employed in this work.

\begin{tabular}{lccll}
\hline $\begin{array}{l}\text { Proxy } \\
\text { number }\end{array}$ & $\begin{array}{l}\text { Start } \\
\text { Year }\end{array}$ & $\begin{array}{l}\text { End } \\
\text { Year }\end{array}$ & Reference & $\begin{array}{l}\text { Source Proxy } \\
\text { Location }\end{array}$ \\
\hline 1 & 1300 & 1978 & Cook (2008) & North America \\
2 & 1408 & 1978 & Cook (2000) & North America \\
3 & 1525 & 1982 & Braganza et al. (2009) & Pacific Basin \\
4 & 1590 & 1990 & Evans et al. (2001) & America \\
5 & 1607 & 1981 & Dunbar et al. (1994) & Eastern Equatoiral Pacific \\
6 & 1635 & 1998 & Cobb et al. (2003) & Central Equatorial Pacific \\
7 & 1650 & 1990 & Mann et al. (2000) & Near Global (tropics) \\
8 & 1706 & 1997 & Stahle et al. (1998) & Pacific Basin \\
9 & 1727 & 1982 & Braganza et al. (2009) & Pacific Basin \\
10 & 1800 & 1990 & Evans et al. (2002) & Indo-Pacific Basin \\
\hline
\end{tabular}

more than one of the proxy input networks. Further to this, it is clear looking at the geographic distribution and type of the input proxies used in these 9 selected ENSO proxies that the selected network is derived from a truly diverse multiproxy input network (Table 1, Fig. 2). Whilst details about the source data of Cook et al. (2008) are not published as yet, the new proxy network contains many additional data which results in relatively small data redundancy (approximately $25 \%$ ) between the new tree ring derived reconstruction of Cook et al. (2008) and the previously published tree ring derived reconstruction of Cook (2000) (Cook, personal communication, 2009). Considering that the diversity and distribution of the network has been proposed to reduce the effects of biases and weaknesses in the individual indicators, we expect that the use of this network of ENSO proxies will allow us to more accurately capture the climatic signal of ENSO variability. However, we must note that the North American region could be overrepresented as 7 out of the 10 input ENSO reconstructions used in this study utilise North 


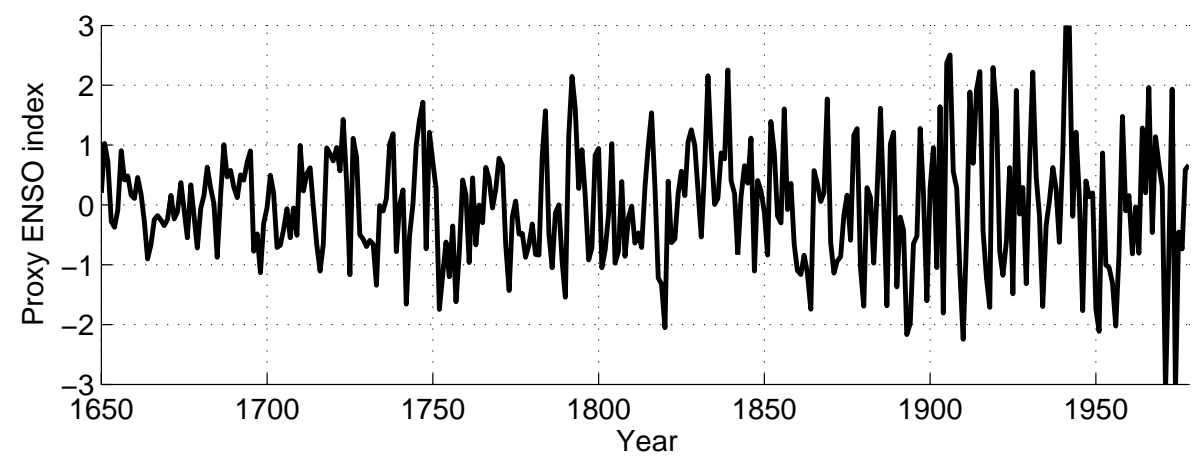

Fig. 3. The unified ENSO proxy (UEP) for the period 1650-1978.

Table 2. \% variance explained by the first four principal components along with the normalized eigenvectors for each proxy.

\begin{tabular}{lllll}
\hline Proxy & PC1 & PC2 & PC3 & PC4 \\
\hline Variance & $52.5 \%$ & $13.9 \%$ & $9.7 \%$ & $7.1 \%$ \\
Proxy 1 & $12.3 \%$ & $9.0 \%$ & $7.6 \%$ & $14.5 \%$ \\
Proxy 2 & $12.3 \%$ & $7.1 \%$ & $4.1 \%$ & $17.5 \%$ \\
Proxy 3 & $12.4 \%$ & $10.5 \%$ & $2.9 \%$ & $8.2 \%$ \\
Proxy 4 & $10.1 \%$ & $3.2 \%$ & $2.1 \%$ & $21.9 \%$ \\
Proxy 5 & $0.0 \%$ & $14.0 \%$ & $46.4 \%$ & $2.6 \%$ \\
Proxy 6 & $7.5 \%$ & $25.5 \%$ & $12.0 \%$ & $2.3 \%$ \\
Proxy 7 & $11.3 \%$ & $3.4 \%$ & $7.8 \%$ & $5.7 \%$ \\
Proxy 8 & $12.9 \%$ & $1.8 \%$ & $1.7 \%$ & $8.5 \%$ \\
Proxy 9 & $13.1 \%$ & $4.4 \%$ & $2.9 \%$ & $11.6 \%$ \\
Proxy 10 & $7.8 \%$ & $21.0 \%$ & $12.3 \%$ & $7.0 \%$ \\
\hline
\end{tabular}

American tree ring data in their ENSO reconstruction derivation. This may result in a common mode that is more highly weighted to this ENSO teleconnection region.

\section{Methods}

The various forms of analysis used to generate ENSO proxies from the original multi-proxy network were carried out to isolate the ENSO variability within the network by removing the effects of climatic noise (i.e., local climatic and other large scale variability uncorrelated to ENSO) and nonclimatic factors (i.e., biological processes). However, due to the large variability between these indices we believe that each of the proxies utilized incorporates, to varying degrees, a noise component that is not related to ENSO (cf. Fig. 1b). Thus, to decompose this new multi-variable ENSO proxy network into a single leading mode of covariability, we carry out a Principal Component Analysis (PCA). The PCA analysis removes variability that is not coherent across the input network by essentially making coherent signals within the network of ENSO proxies leading order modes while variability that is not coherent across the network generally makes up the lower order modes. As such, we expect the first principal component (PC) of the PCA analysis to represent the common signal in each of the selected proxies, ENSO. Furthermore, the PCA also gives us eigenvectors which indicate how important each original input ENSO proxy is in the resultant principal components.

To this end, the PCA analysis was carried out on the ENSO proxy network over the period 1650-1977. Normally, the output of a PCA would not be calibrated to the observations, however, here as several of the input proxies are calibrated the resulting ENSO proxy (the UEP) is not completely uncalibrated to the twentieth century observations. The first PC of the PCA analysis displayed in Fig. 3 accounts for approximately $52 \%$ of the ENSO proxy covariability (see Table 2). PC1's associated eigenvectors, displayed in Table 1, indicate that the weighting is relative equally distributed across 9 of the 10 proxies used with the only outlier being the coral derived proxy of Dunbar et al. (1994) which has a weighting of approximately 0 . The remaining PCs account for $48 \%$ of the ENSO proxy covariability, where the second, third and forth PCs accounting for approximately $14 \%, 10 \%$ and $7 \%$ of the variance, respectively.

The agreement between the first PC and the original input proxies is assessed by calculating the correlation coefficients between the time series. As expected when considering the eigenvectors of PC1, 9 of the original 10 input ENSO proxies have extremely good correlations with the PC1 that are statistically significant above the 99\% level (Table 3). Further, we find that PC1 correlates extremely well with the mean of the 10 original input proxies where the correlation coefficient is 0.98 . We note here however, that although the PC1 correlates well with mean of the input proxies there are some significant differences in the magnitude of the variability that is most prominent in the years surrounding 1700 and 1900 (figure not shown). Thus, it appears that the first PC captures the common signal in the input proxies. As such, we will hereafter call the first PC of this analysis the "Unified ENSO Proxy" (UEP).

To test the robustness of the UEP to the choice and number of multi-proxy based ENSO indices used, and the robustness of the other higher order modes, we carry out a series 
Table 3. Correlation coefficients and root mean squared error (RMSE), in brackets, of the Unified ENSO proxy (UEP) and the original proxy network with the UEP and observations during the overlapping period. Sources: SOI, Ropelewski and Halpert (1987); Kn34, Kaplan et al. (1998); Hn34, Rayner et al. (2003); and Bn34, Bunge and Clarke (2009). Statistical significance of greater than the 99\% level in the correlation coefficients is indicated by bold font.

\begin{tabular}{lrrrrr}
\hline Correlation (RMSE) & UEP & SOI & Kn34 & Hn34 & Bn34 \\
\hline UEP & $\mathbf{1 . 0}(0.0)$ & $-\mathbf{0 . 8 1}(0.58)$ & $\mathbf{0 . 8 1}(0.58)$ & $\mathbf{0 . 8 2}(0.57)$ & $\mathbf{0 . 8 1}(0.59)$ \\
Proxy 1 & $\mathbf{0 . 8 4}(0.54)$ & $-\mathbf{0 . 7 4}(0.67)$ & $\mathbf{0 . 7 0}(0.71)$ & $\mathbf{0 . 7 3}(0.68)$ & $\mathbf{0 . 7 1}(0.69)$ \\
Proxy 2 & $\mathbf{0 . 8 4}(0.54)$ & $-\mathbf{0 . 7 3}(0.68)$ & $\mathbf{0 . 7 1}(0.70)$ & $\mathbf{0 . 7 2}(0.69)$ & $\mathbf{0 . 6 7}(0.74)$ \\
Proxy 3 & $\mathbf{0 . 8 5}(0.52)$ & $\mathbf{0 . 6 2}(0.78)$ & $-\mathbf{0 . 6 4}(0.77)$ & $-\mathbf{0 . 6 5}(0.76)$ & $\mathbf{0 . 6 5}(0.75)$ \\
Proxy 4 & $\mathbf{0 . 6 8}(0.73)$ & $\mathbf{0 . 5 7}(0.82)$ & $-\mathbf{0 . 6 0}(0.80)$ & $-\mathbf{0 . 6 1}(0.79)$ & $\mathbf{0 . 5 8}(0.81)$ \\
Proxy 5 & $0.00(0.99)$ & $0.11(0.99)$ & $-0.02(1.0)$ & $-0.08(0.99)$ & $0.06(0.99)$ \\
Proxy 6 & $\mathbf{0 . 6 1}(0.79)$ & $-\mathbf{0 . 6 2}(0.79)$ & $\mathbf{0 . 6 7}(0.74)$ & $\mathbf{0 . 6 5}(0.75)$ & $\mathbf{0 . 6 7}(0.74)$ \\
Proxy 7 & $\mathbf{0 . 7 6}(0.64)$ & $\mathbf{0 . 7 4}(0.67)$ & $\mathbf{- 0 . 7 4}(0.67)$ & $\mathbf{- 0 . 7 6}(0.64)$ & $\mathbf{0 . 7 7}(0.64)$ \\
Proxy 8 & $\mathbf{0 . 8 6}(0.51)$ & $\mathbf{0 . 7 5}(0.65)$ & $-\mathbf{0 . 7 1}(0.70)$ & $-\mathbf{0 . 6 9}(0.72)$ & $\mathbf{0 . 6 9}(0.72)$ \\
Proxy 9 & $\mathbf{0 . 8 7}(0.49)$ & $\mathbf{0 . 7 0}(0.71)$ & $-\mathbf{0 . 6 9}(0.72)$ & $\mathbf{0 . 7 0}(0.71)$ & $\mathbf{0 . 6 9}(0.72)$ \\
Proxy 10 & $\mathbf{0 . 4 9}(0.87)$ & $\mathbf{0 . 5 8}(0.81)$ & $\mathbf{- 0 . 6 5}(0.76)$ & $-\mathbf{0 . 6 9}(0.73)$ & $\mathbf{0 . 6 7}(0.73)$ \\
\hline
\end{tabular}

of sensitivity tests. These tests are specifically designed to answer the questions: if only a subset of the available ENSO proxies were selected would the output of the PCA change? how much does it matter which proxies are selected? and does it make a difference if no calibrated input proxies are used?

Starting with only testing the robustness/sensitivity of the first principal component we generate subsets of ENSO proxies, each of the new proxy subsets are combinations containing 5 of the 10 original ENSO proxies. In total we have 252 subset networks which cover all possible combinations of 5 proxies from the original ENSO proxy network (hereafter referred to as the 10choose 5 proxy network). We now carry out a PCA on each proxy subset within the 10choose5 proxy networks, giving 252 first principal components (one for each subset). We then seek to identify what the dominant signal is among these 252 normalized first PCs. There are three ways we can identify the dominant signal in this network. Using the first method we would carry out a PCA to identify the dominant mode, while using the second (third) method we would simply calculate the mean (median) of the 252 first PCs at each time point. Each of these methods identifies the same dominant signal in the first PCs with correlations between each method having coefficients $>0.999$. Further, this dominant signal has a correlation coefficient of $>0.998$ when compared with the UEP.

Now to assess the robustness of this new ENSO proxy we use the signal to noise ratio (SNR) of the 10choose5 proxy network first PCs, whereby the higher the ratio the less dominant the noise component becomes. The SNR of each of the 252 first modes is defined by the equation:

$\mathrm{SNR}=\left(\frac{\sigma_{\text {signal }}}{\sigma_{\text {noise }}}\right)^{2}$

where $\sigma$ is the standard deviation, the signal is defined as the median of the 252 first modes at each time point (which is correlated at 0.998 when compared with the new ENSO proxy) and the noise component of each of the 252 first PCs is defined as the component remaining when the signal is subtracted from the each of the 252 first PCs. We would expect that if the dominant mode of covariability identified by our initial analysis was not robust the signal to noise ratio (SNR) would be low. Meaning, which of the original ENSO proxies we select to include in our analysis is extremely important as the noise can easily dominate the signal of our newly defined ENSO proxy. On the other hand, if proxy choice is not important the SNR should be large, such that any choice of proxies should identify a very similar dominant mode

We find that the UEP signal (the new ENSO proxy) dominates the noise component (meaning a $\mathrm{SNR}>1$ ) regardless of which 5 of the original ENSO proxies we select for our analysis. The mean SNR of all of the 252 first principal components is 11.83 and the minimum and maximum SNRs are 2.55 and 26.61 respectively. Further to this, the higher the number of proxies selected from the original network (e.g., if we generate a 10 choose 6 or 10 choose 7 proxy network and carryout the same analysis described above), the larger the SNR becomes and the more dominant the UEP signal becomes. For the 10choose6 (10choose7) case the mean SNR becomes 17.95 (28.35) while the minimum and maximum SNR become 4.89 (9.90) and 43.82 (66.56). Therefore, the UEP is robust regardless of the number of proxies selected (assuming it is $\mathbf{5}$ or more) and what proxies are selected from the original network (i.e., whether proxies are included that were calibrated to 20th century observations).

On the other hand, if the same set of sensitivity tests described above are carried out for PC2 then the average SNR is much lower (mean SNR of 1.55) and, depending on the selection of original proxies used, the amplitude of the noise can become larger than that of the signal (meaning a $\mathrm{SNR}<1$ ). 

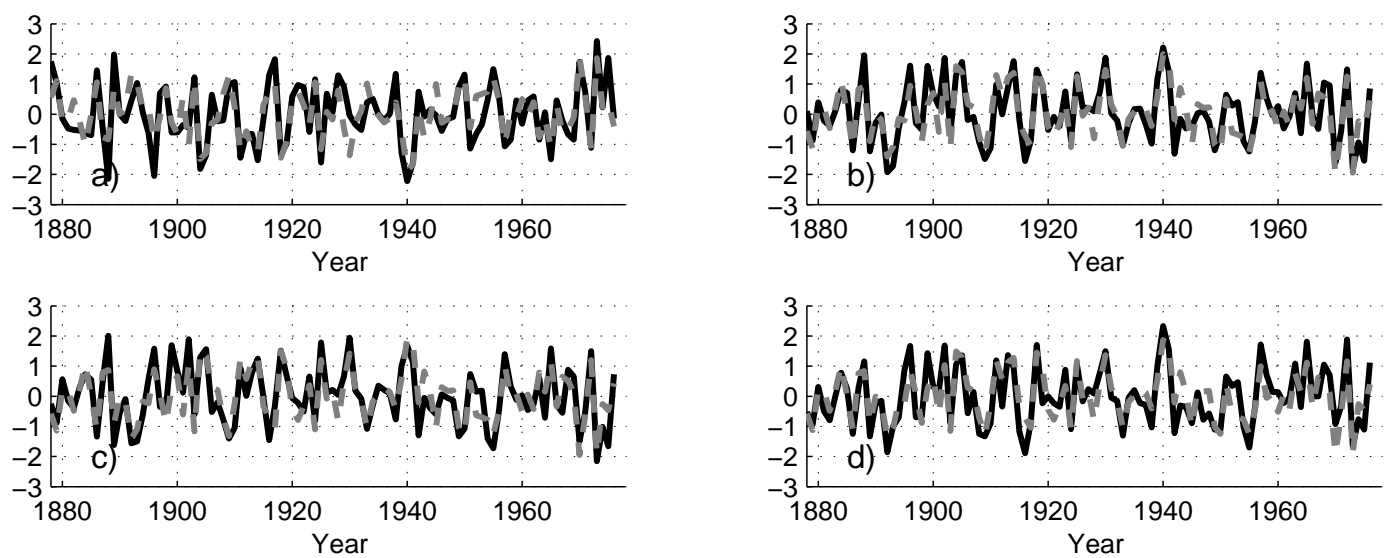

Fig. 4. The time series of observed (a) SOI, (b) Kn34 SSTA, (c) Hn34 SSTA, and (d) Bn34 SSTA are represented by the solid black line while overlaid as a gray dashed line is the UEP.

Since this result holds regardless of the number of proxies selected from the original proxy network, the second principal component is not robust and is easily contaminated with noise.

\section{Unified ENSO proxy}

In this section we compare the time series of the newly developed unified ENSO proxy (UEP) to instrumental ENSO indices over the 20th century and documented historic ENSO chronologies. The comparisons are done using different methods which include temporal correlation and skill in the ability of the proxy to simulate threshold based ENSO events.

\subsection{Comparison with the instrumental record}

Normalized anomalies of observed annual mean (calculated over the months July-June) values of the Southern Oscillation Index (SOI) for the period 1876-1977 were obtained from Ropelewski and Halpert (1987). While SST anomaly (SSTA) data for the Niño 3.4 region region $\left(5^{\circ} \mathrm{S}-5^{\circ} \mathrm{N}\right.$, $120^{\circ} \mathrm{W}-170^{\circ} \mathrm{W}$ ) for the period $1856-1977,1870-1977$ and 1873-1977 was obtained respectively from Kaplan et al. (1998), Rayner et al. (2003) and Bunge and Clarke (2009). These three Niño 3.4 region SSTA time series will hereafter be referred to as $\mathrm{Kn} 34, \mathrm{Hn} 34$ and $\mathrm{Bn} 34$.

The correlation coefficients ( $\mathrm{R}$ ) between the UEP and SOI, $\mathrm{Kn} 34, \mathrm{Hn} 34$ and Bn34 are $-0.81,0.81,0.82$ and 0.81 respectively and each of these coefficients is statistically significant above the 99\% confidence level (see Table 3 and Fig. 4). We note that the statistical significance of all correlation coefficients presented in the study take into account serial (auto-) correlation in the series based on the reduced effective number of degrees of freedom outlined by Davis (1976). These correlation coefficients are larger than any of the correlation coefficients generated when comparing the 10 original input proxies versus observed indices of ENSO. Furthermore, using a least squares linear regression model for each of the original ENSO proxies along with the new ENSO proxy we find the the new ENSO proxy has the smallest root mean square error (Table 3). Therefore, this confirms that the PCA analysis has acted to isolate the common ENSO related component of each of the original input proxies into $\mathrm{PC} 1$, our new ENSO proxy.

Using the RMSE, which is an estimate for the standard deviation of the scatter about the regression line, we calculate the two sided $90 \%$ confidence interval for output of the regression model (von Storch and Zwiers, 2000) (page 154). This confidence interval, which is slightly less than one standard deviation, gives an approximate range in which the true unobserved ENSO index value is expected with $90 \%$ chance. Note, we neglect the uncertainty associated with the estimate of the slope which is small compared with the RMSE. Further to this, there are nonlinearities within certain sub-samples of ENSO timeseries (i.e., periods in the observational record in which ENSO indices display significant skewness). During these periods outliers may therefore occur more frequently than expressed by the nominal confidence level. With the above caveats in mind, the confidence levels are useful for the identification of accurate thresholds for the detection of discrete ENSO events. For example, if we want to make sure that an identified El Niño year was not associated with a true La Niña event with $95 \%$ confidence, one must choose a threshold level such that the lower confidence range around the reconstructed ENSO estimate is above the La Niña event threshold. In the case of ordinary linear regression this threshold level can be found in Fig. 5 where the lower confidence limit intersects the horizontal line marking the La Niña threshold. Given that the confidence interval for our regression model is approximately one standard deviation, a threshold level for ENSO events of 0.5 

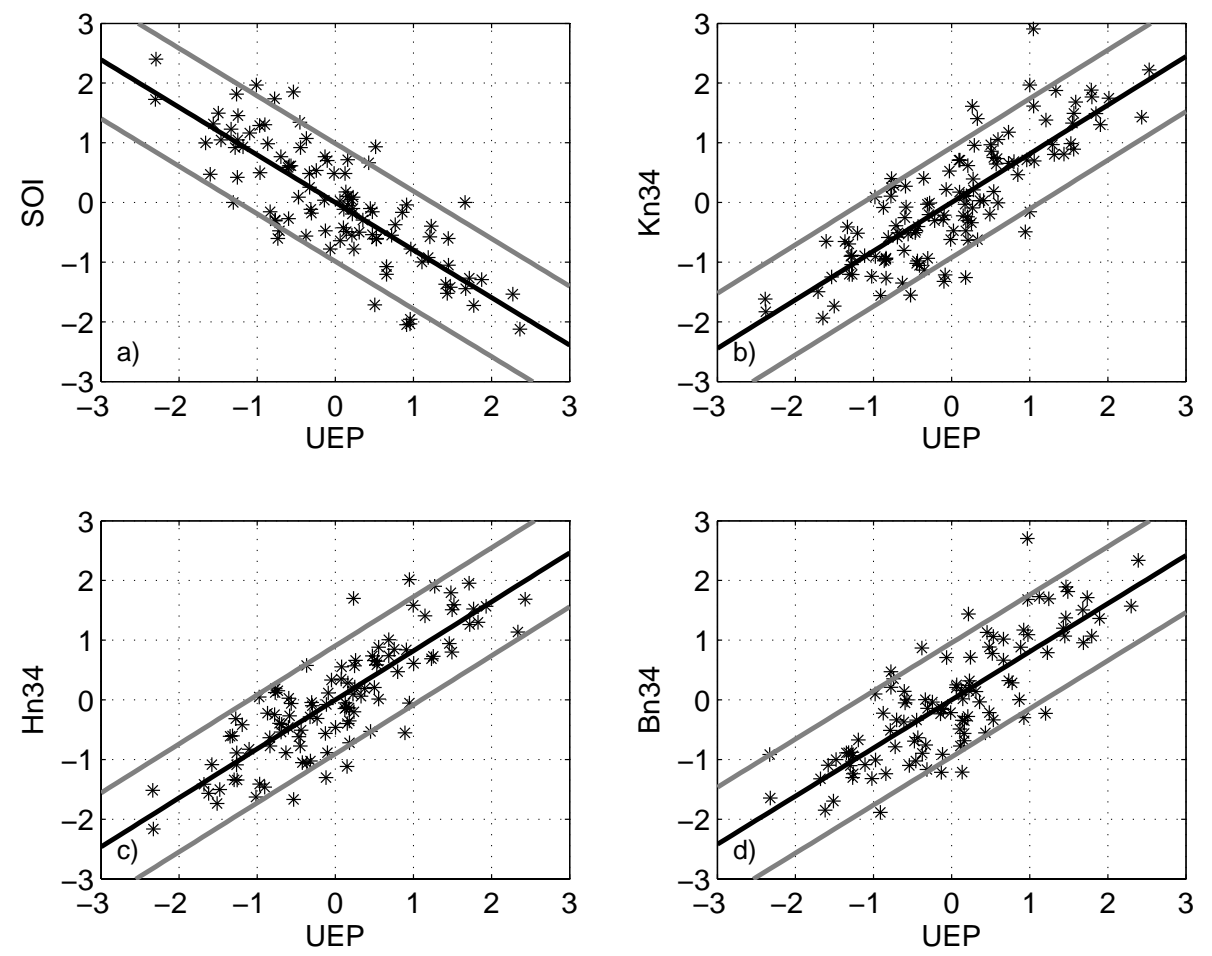

Fig. 5. The least squares linear regression line (shown in black) between the UEP and the (a) SOI, (b) Kn34 SSTA, (c) Hn34 SSTA, and (d) Bn34 SSTA, while the gray lines indicate the $95 \%$ confidence interval.

Table 4. Direct correspondence of El Niño (La Niña) events between the unified ENSO proxy (UEP) and observations. Observed sources: SOI, Ropelewski and Halpert (1987); Kn34, Kaplan et al. (1998); Hn34, Rayner et al. (2003); Bn34, Bunge and Clarke (2009).

\begin{tabular}{lrrrr}
\hline Correspondence & SOI & Kn34 & Hn34 & Bn34 \\
\hline Obs hits & $74.2 \%(75.0 \%)$ & $80.6 \%(74.2 \%)$ & $75.8 \%(70.0 \%)$ & $76.7 \%(70.6 \%)$ \\
Obs misses & $25.8 \%(25.0 \%)$ & $19.4 \%(25.8 \%)$ & $24.2 \%(30.0 \%)$ & $23.3 \%(29.4 \%)$ \\
UEP false events & $20.6 \%(29.4 \%)$ & $13.8 \%(32.3 \%)$ & $13.8 \%(38.2 \%)$ & $20.7 \%(29.4 \%)$ \\
\hline
\end{tabular}

standard deviations above or below the mean satisfies this criteria. This threshold value is roughly consistent with the Niño 3.4 region SSTA threshold used for the definition of ENSO events by NOAA (which is $0.5^{\circ} \mathrm{C}$ above or below the mean state, calculated from the period 1971-2000, where the standard deviation of observed Niño 3.4 region SSTA for the period $1971-2000$ is $0.93^{\circ} \mathrm{C}$ ).

The accuracy of the UEPs ability to capture discrete El Niño and La Niña events in the period 1878-1977 is then assessed. Using this 0.5 standard deviation threshold for ENSO events means that approximately $\frac{1}{3}$ of all years are classified as either El Niño, La Niña or Neutral. Looking at the correspondence between the UEP and observations we find that: (i) of the 31 (32) El Niño (La Niña) events identified in the SOI between 1878 and 1977 the UEP correctly identifies 23 (24); (ii) of the 31 (31) El Niño (La Niña) events identified in Kn34 between 1878 and 1977 the UEP correctly identifies 25 (23); (iii) of the 33 (30) El Niño (La Niña) events iden- tified in Hn34 between 1878 and 1977 the UEP registers 25 (21) of these; and (iv) of the 30 (34) El Niño (La Niña) events identified in Bn34 between 1878 and 1977 the UEP registers 23 (24) of these (see Table 4 for more details). Hence, approximately $77 \%$ of the El Niño events and $72 \%$ of La Niña events during the period 1878-1977 are captured by the UEP. Looking at the false alarm rate of the new ENSO proxy we find that there were: (i) 6 (10) false El Niño (La Niña) alarms raised that were not identified in the SOI; (ii) 4 (11) false El Niño (La Niña) alarms raised that were not identified in Kn34; (iii) 4 (13) false El Niño (La Niña) alarms raised that were not identified in Hn34; and (iv) 6 (10) false El Niño (La Niña) alarms raised that were not identified in Bn34. Consistent with other studies (e.g., Braganza et al. (2009)) the UEP shows higher skill in reproducing warm (El Niño) events than the opposite phase.

Comparing the accuracy of the UEPs ability to capture discrete ENSO events to the event capture of the 10 original 

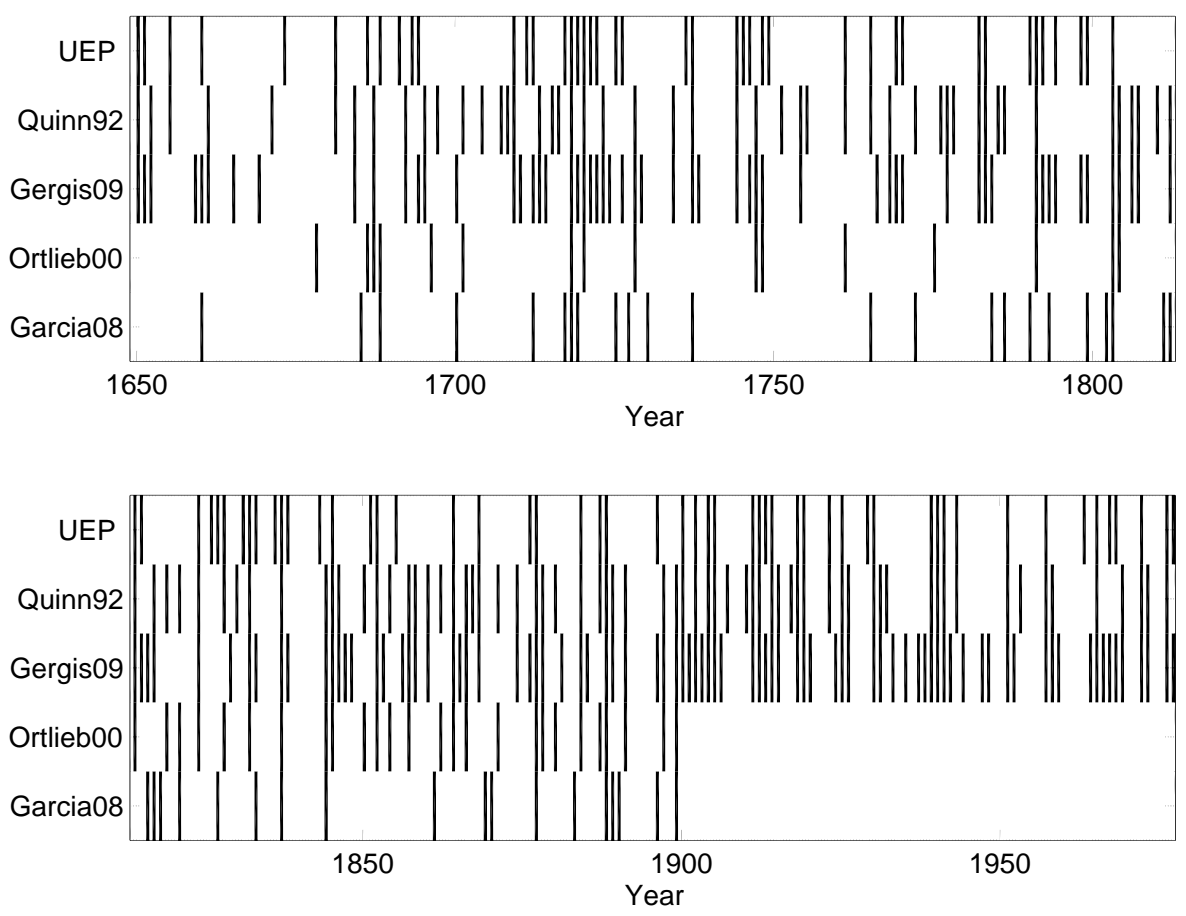

Fig. 6. Chronologies of El Niño in the 1650-1978 period where vertical bars indicate the year ${ }_{0}$ of the El Niño event. Here the row labeled UEP indicates El Niño events identified in the UEP by the $\frac{1}{2}$ standard deviation threshold, while QN92 refers to Quinn and Neal (1992), Orlieb00 refers to Ortlieb (2000), Garcia08 refers to Garcia-Herrera et al. (2008) and Gergis09 refers to Gergis and Fowler (2009).

proxies (using the same 0.5 standard deviation threshold to define El Niño and La Niña years), we find that the UEP captures more El Niño events in the observational period and has a lower false alarm rate than any of the original proxies. In regards to the La Niña event capture, we find that the UEP again captures more events than any of the 10 original proxies. However, while the false alarm rate is relatively low at $16 \%$, the false alarm rates of the Stahle et al. (1998), Mann et al. (2000) and Cook et al. (2008) ENSO proxies are slightly lower at $10 \%, 14 \%$ and $12 \%$.

\subsection{Comparison with historic ENSO chronologies}

In this section we continue our assessment of the accuracy of the UEPs ability to capture discrete El Niño and La Niña events. However, here instead of assessing the UEP against instrumental observations, we will be assessing the correspondence between the UEP and documented historical chronologies of El Niño (Quinn and Neal, 1992; Ortlieb, 2000; Garcia-Herrera et al., 2008; Gergis and Fowler, 2009) and La Niña (Gergis and Fowler, 2009) events.

These historic chronologies of ENSO namely utilize documentary sources of meteorological and climatic extremes from regions with weather conditions that are normally heavily influenced by ENSO events to provide a mainly binary type representation of ENSO variability. The most widely referenced of these chronologies is the El Niño chronology of
Quinn and Neal (1992). This chronology, beginning in 1520 and ending in 1990, records El Niño years charactorized by unusual climatic events in the South American region. The Quinn and Neal (1992) chronology has since been revised by Ortlieb (2000) to try and account for the ambiguity introduced into the Quinn record by using secondary documentary sources and climatic events in regions where weather is only weakly related to El Niño. This revised work of Ortlieb (2000) covers the period 1520 through to and including the year 1900. The more recent documented historical El Niño chronology of Garcia-Herrera et al. (2008), for the period $1550-1900$, is based primarily on documentary records in Northern Peru. The final ENSO chronology used for verification in this study is that of Gergis and Fowler (2009). While the above chronologies all primarily used documentary evidence to assemble their chronologies, the study of Gergis and Fowler (2009) constructs a chronology of both El Niño and La Niña events using a combination of Paleoclimatic data and chronologies of ENSO variability. We note here that in cases when magnitude information is also included as part of the ENSO chronology, this extra information is disregarded and the information provided is simply used as binary type information.

Looking at the direct correspondence between the UEP and chronologies of Quinn and Neal (1992) and Gergis and Fowler (2009) we find that of the 101 El Niño events identified in the UEP between 1650-1977, approximately $51 \%$ 
Table 5. Direct and quasi-direct (in parentheses) correspondence between the unified ENSO proxy (UEP) and chronologies of El Niño where QN92 = Quinn and Neal (1992), Orlieb00 = Ortlieb (2000), Garcia08 = Garcia-Herrera et al. (2008) and Gergis09 = Gergis and Fowler (2009). Quasi-direct correspondence counts direct correspondence along with events in the chronology that lag 1-yr behind the UEP El Niño event.

\begin{tabular}{lrrrr}
\hline Correspondence & QN92 & Ortlieb00 & Garcia08 & Gergis09 \\
\hline Obs hits & $51.1 \%(75.5 \%)$ & $29.0 \%(46.4 \%)$ & $27.5 \%(47.8 \%)$ & $69.1 \%(91.5 \%)$ \\
Obs misses & $49.9 \%(24.5 \%)$ & $71.0 \%(53.6 \%)$ & $72.5 \%(52.2 \%)$ & $30.9(8.5 \%)$ \\
\hline
\end{tabular}

(69\%) are registered in the Quinn and Neal (1992) (Gergis and Fowler, 2009) chronology (Fig. 6 and Table 5). Also, of the 110 La Niña events identified in the UEP, $57.3 \%$ are registered in the chronology of Gergis and Fowler (2009). Assessing the direct correspondence between the UEP and the El Niño chronologies of Ortlieb (2000) and Garcia-Herrera et al. (2008), over the period 1650-1900, we find that of the 75 El Niño events registered in the UEP, approximately $29 \%$ and $28 \%$ are respectively registered in the Ortlieb (2000) and Garcia-Herrera et al. (2008) chronologies (Fig. 6 and Table 5). To assess the statistical significance of this correspondence we used a Monte Carlo type approach whereby we calculated 1000 Fourier based surrogates of the newly defined UEP using the method described by Theiler et al. (1992). These surrogates share the same mean, variance and power spectrum as the UEP, however, their phases are randomly shuffled. We then calculated the direct correspondence between each of these surrogates and the four El Niño chronologies and one La Niña chronology described above. We find that the correspondence between the UEP and the ENSO chronologies is statistically significant above the $99 \%$ level. Further to this, the correspondence between the UEP and these ENSO chronologies is larger than the correspondence between the ENSO chronologies and any of the 10 original ENSO proxies.

In order to get a more accurate representation of the UEP ENSO event capture we now make the assumption that the effects of UEP defined ENSO events could be felt in the ENSO chronologies in the year of the event or the year following (quasi-direct correspondence). This allows for the effects of annual averaging in the proxies and delayed ENSO teleconnections in the chronologies. For example, consider a typical El Niño year, when taking an annual average of this events SSTA it is normally attributed to the year the event develops (year-0) instead of the year the event decays (year1). Now, if we consider the climatic effects of this event, composite analysis reveals that El Niño related South American rainfall anomalies also straddle year 0 and year 1 (Ropelewski and Halpert, 1987). As such, a large rainfall event that occurred and was documented in the year after the event (year 1) could easily be attributed to the event in the year prior. Using this quasi-direct approach we find that the number of corresponding El Niño events between the UEP and the chronology of Quinn and Neal (1992) changes from 51\% to $75.5 \%$, while the number of corresponding La Niña events between the UEP and the chronology of Gergis and Fowler (2009) changes from $57.3 \%$ to $85.5 \%$ (Table 5). We note that while this jump in correspondence between the direct to quasi-direct is quite large, it is consistent with expectations as this method essentially increases the degrees of freedom of the relationship. Using the same Monte Carlo type approach as described in the paragraph above, we find that the quasi-direct correspondence between the UEP and each of the ENSO chronologies is again statistically significant above the $99 \%$ level. Furthermore, this quasi-direct correspondence between the UEP and these ENSO chronologies is also larger than the quasi-direct correspondence of any of the 10 original ENSO proxies.

\section{ENSO variability since 1650}

We have shown that the newly defined UEP provides an accurate representation of ENSO variability, and while it corresponds well with the original proxy network, it provides a better representation of observed indices and documented historical chronologies of ENSO. Here we describe various changes in the UEP, and hence ENSO, which have occurred since 1650 focusing on (a) changes in ENSOs variance, (b) multi-year ENSO events, (c) multi-decadal variability, and (d) the effects of volcanic and solar forcing on ENSO.

\subsection{Changes in ENSO variance}

To assess the changes in ENSO variance since 1650 we calculate the variance of the UEP in a 16-yr running window (Fig. 7b). However, prior to this the UEP variance is scaled to that of the HadSST1 annual mean (July-June) Niño 3.4 region SSTA (Hn34) in the overlapping period using UEP $\times \frac{\sigma_{\mathrm{Kn} 34}}{\sigma_{\text {UEP }}}$. The UEP is then extended to the year 2004 by adding the HadSST1 data onto the end of the UEP record (Fig. 7a). Visual analysis of the 16-yr running variance reveals one obvious feature, a strong linear increasing trend. Thus, the period from 1650 to the early 1700 s a period of low variance while the twentieth century is generally a period of high variance. We note, however, that this increasing trend is punctuated by a multi-decadal signal which creates low and high variance periods relative to the variance trend. There are various possible causes for these changes in ENSO 

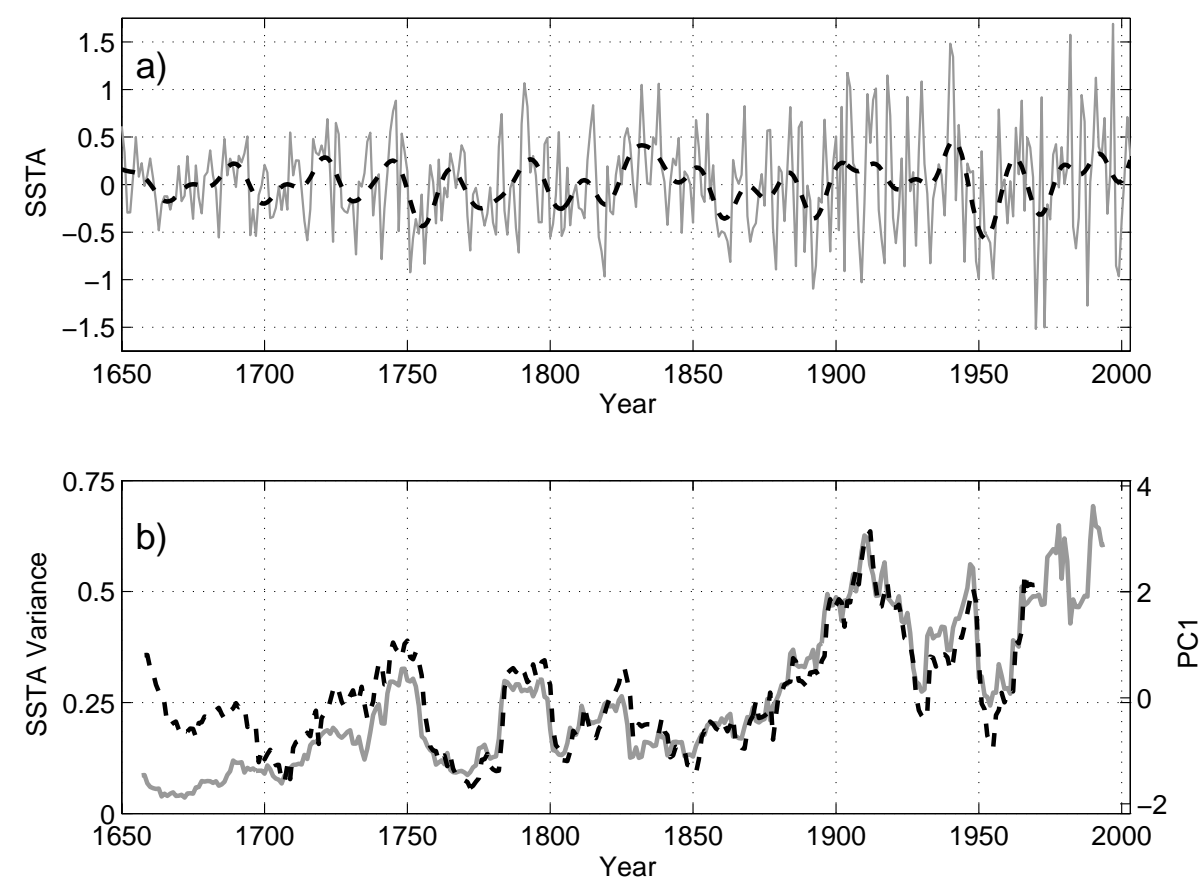

Fig. 7. (a) The scaled UEP (gray) and its 13-yr low-pass filtered variability (black dashes); (b) The 16-yr running window variance of the scaled UEP is shown in gray while the first PC of the running variance of all 10 input proxies is shown in black dashes.

variance. They are, that the variance changes represent: (i) changed strength in the teleconnection patterns of ENSO; (ii) dating uncertainties within the source ENSO reconstructions, which if present generally increase back through time, reducing the amplitude of the common signal; (iii) proxy data quality problems; or (iv) real ENSO variability. Here, we will investigate each of these possible causes to try and ascertain whether these changes in variance represent the real ENSO signal.

Firstly, we note that there is high correspondence between the running variance of the UEP and that of the annual average (July-June) of the verified Niño 3.4 region SSTA of Bunge and Clarke (2009), where the correlation coefficient of 0.7 is statistically significant above the $99 \%$ level. As such the 20th century variance of the UEP is realistic. Secondly, while establishing the robustness of the UEP (see Methods section) 252 first PCs were generated from the 10choose5 network. To assess the robustness of the of these variance changes to the choice of input proxies used we calculated the 16-year running variance of each of these first PCs and compared it (by calculating the correlation coefficient) with that of the UEP. We find that all 252 correlation coefficients are statistically significant above the $99 \%$ level and larger than 0.83 . Thus, the changes in UEP running variance are robust regardless of what proxies are selected from the original network (i.e., whether proxies are included that were calibrated to 20th century observations).

In regards to the effects of the changing strength of ENSO teleconnection patterns on ENSO reconstruction variance, we have effectively reduced the effects of this by identifying the UEP in a network of ENSO reconstructions derived from globally distributed proxy data. The use of a PCA on the global proxy network diminishes the impact of regional specific changes in the signal by identifying the dominant changes in the entire network.

To identify the effects of proxy data quality problems we first analyze the variability amongst the 10 different input ENSO reconstructions. We would expect that if the quality of the proxy reconstructions were to deteriorate an increase in spread among the proxies would be seen. However, this is not apparent (Fig. 1b), so we do not believe that the quality of data systematically decays throughout the period 1650 1977.

To understand the effects of dating uncertainties in the input ENSO reconstructions we calculate the 16-yr running variance of each of the original 10 proxies. Calculation of the running variance reduces the effects of dating uncertainties in the ENSO reconstructions by not allowing slightly shifted signals to damp out the common signal variance. We then seek to identify the common running variance signal within these input reconstructions by calculating a PCA on the running variances. The first PC of this analysis, which accounts for $42 \%$ of the original proxy data variance, has a correlation of 0.86 with the 16-yr running variance of the UEP (Fig. 7b). Hence, the UEP running variance is representative of the dominant variance changes in the original ENSO proxies. We note however, that the time series of the UEP running variance and the first PC of the original proxy 

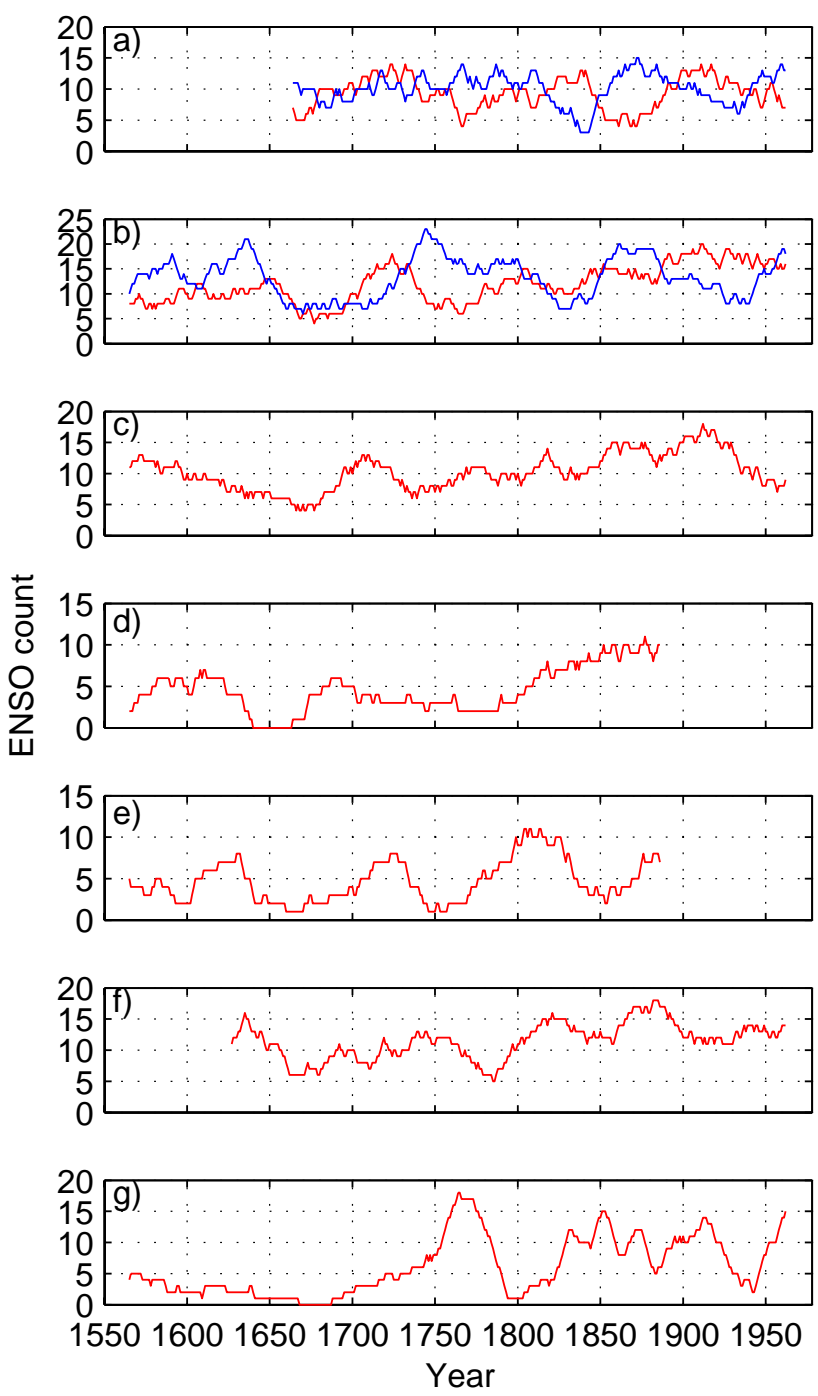

Fig. 8. The number of El Niño (red) and La Niña (blue) events in a 30 -yr centered running window from (a) the UEP (using a 0.5 standard deviation threshold for ENSO events), the historical chronologies of (b) Gergis and Fowler (2009), (c) Quinn and Neal (1992), (d) Ortlieb (2000), (e) Garcia-Herrera et al. (2008), and the proxy records of Boës and Fagel (2008) and Hendy et al. (2003) which again use a 0.5 standard deviation threshold for El Niño events.

running variance do diverge near the beginning of the record indicating that dating uncertainties begin to become important.

This suggests that the changes in variance of the UEP represent a real signal in the original ENSO reconstructions. We now assess these changes in UEP variance with historic documentary and unused paleo proxies to further verify the realism of these variance changes. We find that both the increasing trend in variance and the low variance period from 1650-1720 are supported by the 4 historical documentary chronologies of El Niño variability already discussed in this study (Quinn and Neal, 1992; Ortlieb, 2000; Garcia-Herrera

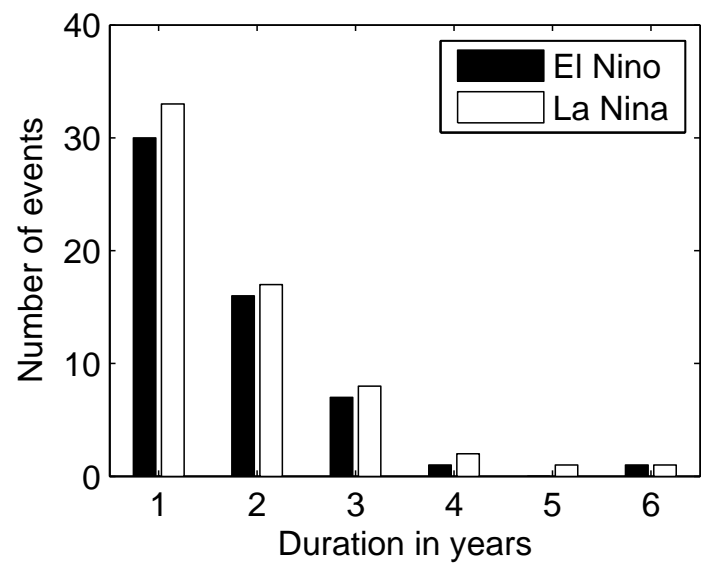

Fig. 9. The number of ENSO events that persist un-interrupted for 1-6-yrs.

et al., 2008; Gergis and Fowler, 2009). In regards to the increasing trend in variance, there is a statistically significant (above the 95\% level) linear increasing trend in the number of El Niño events that occur in the 30-yr running windows in the period starting 1650 and ending at the end of each record of the four chronologies (Fig. 8b-e). While in regards to the low variance period of the late 17th century each of these chronologies displays a reduction in the number of El Niño events during this period (Fig. 8b-e). It is not likely that the decreasing number El Niño events back to this period or the low levels in the late 1600s are due to lack of documentation as all chronologies show a larger number of El Niño events in the period prior to 1650 .

Further to this, both of these features are also supported by the Great Barrier Reef coral luminescence record of Hendy et al. (2003) (Fig. 8f). We note that while this time series was used in the proxy network of Braganza et al. (2009) to develop the ENSO proxy (ENSO proxy 9 in this study) for the period 1727-1982, it was unused for the low variance period (1650-1720) and thus provides additional independent supporting evidence for the low ENSO variability of this period. Additionally, the low variance period of 1650-1720 is also supported by the varved lake sediment proxy data of Boës and Fagel (2008) (Fig. 8g), while the linearly increasing trend is supported by the Galapagos, El Junco lake diatom ratio's (Conroy et al., 2009). Here, we note that while the Boës and Fagel (2008) data are from Southern Chile, at a latitude that one would not expect to be significantly influenced by ENSO variability, the data are significantly (>99\%) correlated (correlation coefficient of -0.58 ) with the SOI between 1968 and 1997 and composites of rainfall variability for June-August period following an El Niño event display significant decreases in rainfall in the lake region (not shown). As such, all the evidence available suggests that the changes in UEP running variance are realistic and representative of changes in ENSO variance. 


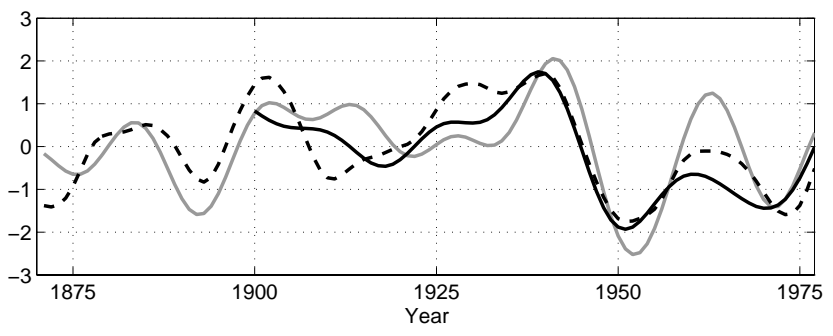

Fig. 10. The normalized 13-yr low-pass filtered time series of the UEP (gray) and PDO (black) along with time series of the IPO (black dashes).

\subsection{Multi-year ENSO events}

In the early 1990s the tropical Pacific Ocean displayed large scale El Niño-like conditions which persisted for 5-yrs. So unusual was this event in the observational record that manuscripts discussing or seeking to understand this variability became prevalent in the scientific literature (Kessler and McPhaden, 1995; Trenberth and Hoar, 1996; Latif et al., 1997). The title of Latif et al. (1997) explains the range of possible forcing mechanisms discussed in the scientific literature, "Greenhouse warming, Decadal variability, or El Niño? An attempt to understand the anomalous 1990s". Interestingly, given the observations of the 20th century the study of Trenberth and Hoar (1996) estimates that the prolonged 1990-1995 El Niño event should occur once in about 1500-3000 years. Here, we use the newly defined ENSO proxy, the UEP, and a half standard deviation threshold to classify ENSO events, to examine just how unusual this multi-year behavior was in the context of ENSO variability of the last 350-yrs. To this end, we calculate the number of times in the UEP record (between 1650-1977) that El Niño (La Niña) conditions persist for 1 through to 6 consecutive years (Fig. 9). We find 7 (4) occurrences of El Niño (La Niña) events that persisted for 3 years and 1 (3) occurrences of El Niño (La Niña) events that persisted for 4 years. The multi-year El Niño events (persisting for 3 or more years) occur reasonably frequently with approximately $2-3$ events occurring every 100 -yrs, with only the 1600 s not displaying multi-year El Niño events. It is a similar story for multi-year La Niña events with 2-3 events occurring every 100 -yrs and the 1600 s not displaying any persistent negative events. Further to this, we find one occurrence of both $\mathrm{El} \mathrm{Niño} \mathrm{and} \mathrm{La}$ Niña events that persist for 6 consecutive years in the 328 year record. Hence, while the prolonged El Niño event of the early 1990s was unusual, it is neither a one off, nor the longest El Niño event on record.

\subsection{Multi-decadal variability}

The shift towards more El Niño-like conditions in the 1980s and 90s and the two large magnitude El Niños of 1982/83 and 1997/98 generated a lot of interest in scientific community with many studies trying to ascertain the causes of this unusual period. While anthropogenic climate change was suggested as one of the possible mechanisms (Trenberth and Hurrell, 1994; Latif et al., 1997), the realization that this change in the late 1970s was one of several large changes that occurred during the 20th century (Trenberth and Hurrell, 1994; Zhang et al., 1997) led a large number of studies to focus on how much of this apparent shift can be explained by a naturally occurring multi-decadal signal. This Pacific Ocean multi-decadal signal of the 20th century is represented by either the Pacific Decadal Oscillation (PDO) of Mantua et al. (1997), which is the North Pacific Ocean's principal mode of decadal variability, or the Interdecadal Pacific Oscillation (IPO) of Power et al. (1999), which is thought of as the Pacific-wide representation of the PDO (Folland et al., 2002).

More recent literature has questioned the statistical robustness of the IPO/PDO as a climate mode, raising the possibility that the PDO/IPO could simply represent low frequency variability of ENSO (Rodgers et al., 2004; Schopf and Burgman, 2006). Regardless of its statistical robustness as a climate mode, it is an intriguing question whether such pronounced multi-decadal variability of the Pacific Ocean existed during the 250 -yrs prior to the 20th century. In order to discuss the multi-decadal variability of the 20th century in the context of the last 350 -yrs, we firstly validate the multidecadal variability of the UEP (Fig. 7a) by comparing it with the multi-decadal variability of observed indices of ENSO, the IPO and PDO (Fig. 10) and the previously defined PDO reconstructions of Biondi et al. (2001) and D'Arrigo et al. (2001). Firstly, however, correlations between the multidecadal variability of the UEP and the original input proxies are presented as a means to assess the contribution of each of the original input proxies to the low frequency variability of the UEP (Table 6). The relative magnitudes of these correlation coefficients are very similar to the relative weightings of the PCA (see Table 2), indicating that the low frequency variability of the UEP represents the multi-decadal variability of the majortity of the original input recontructions.

Comparing the multi-decadal variability (defined as the 13-yr low-pass filtered data) of the UEP and that of the SOI, $\mathrm{Kn} 34, \mathrm{Hn} 34$ and Bn34 gives correlation coefficients $(R)$ of $-0.69,0.66,0.72$ and 0.63 respectively and each of these coefficients is statistically significant above the $95 \%$ confidence level. While the correlation coefficient between the multi-decadal variability of the UEP with that of the IPO (which is 13-yr low-pass filtered by definition) for the period $1870-1980$ is 0.69 , which is statistically significant above the $99 \%$ level. If we low-pass filter annual averages of the PDO with the same 13-yr low pass filter and compare it with the 
low-frequency variability of the UEP over the period 19001980, we find correlation coefficient of 0.75 which is again statistically significant above the $99 \%$ level. Comparing the multi-decadal variability of the UEP with the multi-decadal variability of two previously identified PDO proxies (Biondi et al., 2001; D'Arrigo et al., 2001), we find statistically significant (above the $95 \%$ level) correlation coefficients of 0.40 and 0.59 respectively. Thus, it appears that the UEP displays multi-decadal variability that is consistent with the 20th century variability of ENSO indices, the PDO and IPO, as well as previously defined reconstructions of the PDO. As such, the UEP also provides a means to reconstruct the multidecadal variability of the Pacific Ocean since 1650.

Focusing now on the PDO/IPO-like multi-decadal variability of the last 350-yrs we will assess whether this multidecadal variability has occurred throughout the last 350-yrs. We will then also use the UEP and its low frequency component to analyze whether phase of the PDO/IPO-type variability is related to the variance of ENSO as suggested by the work of Kirtman and Schopf (1998) and Federov and Philander (2000). Firstly, we find significant decadal variability has persisted throughout the last 350-yrs (Fig. 7a) with only a gradual reduction in the 60 -yr running variance occurring (figure not shown). As such, there are numerous periods dominated by multi-decadal El-Niño-like (La Niña-like) behavior like the period from 1830-1860 (1750-1790). If we now bin high frequency values of the UEP (calculated as the residual when the low-frequency UEP is subtracted from the UEP) according to the phase of the low frequency component we do not find a significant relationship between the phase of the PDO/IPO-type multi-decadal variability and variance of the UEPs high frequency variability. This result is consistent with the work of Yeh and Kirtman (2005).

\subsection{The influence of Solar and Volcanic forcing}

Solar variability and explosive volcanic events are both mechanisms that can alter the natural radiative forcing of the climate system. The previous studies of Clement et al. (1996); Cane et al. (1997); Mann et al. (2005) refer to an ocean dynamic thermostat mechanism whereby the temperature of the eastern equatorial Pacific varies negatively with changes in radiative forcing. The study of Meehl et al. (2009) discusses the joint effects of the top-down stratospheric ozone mechanism and the bottom-up coupled air-sea mechanism which cools the equatorial Pacific in response to peaks in solar forcing. Changes in radiative forcing have also been proposed to modulate the variance of ENSO (Mann et al., 2005), whereby low solar forcing periods are proposed to have higher ENSO variance. Using the UEP along with records of solar variability and volcanic forcing we will examine whether the associated radiative forcing plays any role in the mean state or variability changes of ENSO in the last 350-yrs.
Table 6. Correlation coefficient between the 13-year lowpass filtered (LPF) Unified ENSO proxy (UEP) and the 13-year lowpass filtered original proxy network during the overlapping period. Statistical significance of greater than the $99 \%$ (90\%) level in the correlation coefficients is indicated by bold font (italic font).

\begin{tabular}{ll}
\hline Correlation & LPF UEP \\
\hline LPF Proxy 1 & $\mathbf{0 . 7 6}$ \\
LPF Proxy 2 & $\mathbf{0 . 8 0}$ \\
LPF Proxy 3 & $\mathbf{0 . 8 5}$ \\
LPF Proxy 4 & $\mathbf{0 . 7 8}$ \\
LPF Proxy 5 & 0.10 \\
LPF Proxy 6 & 0.50 \\
LPF Proxy 7 & $\mathbf{0 . 6 7}$ \\
LPF Proxy 8 & $\mathbf{0 . 7 6}$ \\
LPF Proxy 9 & $\mathbf{0 . 8 7}$ \\
LPF Proxy 10 & 0.36 \\
\hline
\end{tabular}

Here we investigate the statistical relationship between solar induced changes in radiative forcing and the mean state and variance of ENSO since the year 1650. We test the null hypothesis: solar variability has no influence on the mean state, median or variance of ENSO variability. To this end, we use the reconstruction of solar irradiance of Lean et al. (1995) which spans the period 1610-1994 (see Fig. 2a of Lean et al. (1995)). High (low) solar forcing periods are defined as those years in which the solar forcing is one half a standard deviation or more above (below) the mean. We then bin values of the UEP that correspond to high and low solar variability years separately and test the null hypothesis defined above. Using a t-test we find that there is no statistically significant shift in the mean ENSO state between high and low solar variability phases. Further to this, using the MannWhitney U-test we find no statistically significant change in the ENSO median between the high and low solar variance phases. Thus, this result does not support the proposed thermostat mechanism of Clement et al. (1996). However, using the F-test to assess whether there is a change in variance between the high and low solar phases we find that there is a shift variance that is statistically significant. The result however does not support the results of Mann et al. (2005) as it is found that as solar forcing increases, so to does the variance of ENSO. We note, that if the linear increased trend in solar forcing is removed there is no longer a statistically significant shift in ENSO variance. As such, this relationship between solar forcing and ENSO variance is due to the strong linear increasing trend in both solar forcing and ENSO variance, which does not support any causality. Hence, the null hypothesis can not be rejected with a high degree of confidence. We note that the statistical approach used to asses the relationship between solar forcing and ENSO mean state and variance is a good first step, however, it does not account for non-linearities in the climate system response to changes in solar forcing. 

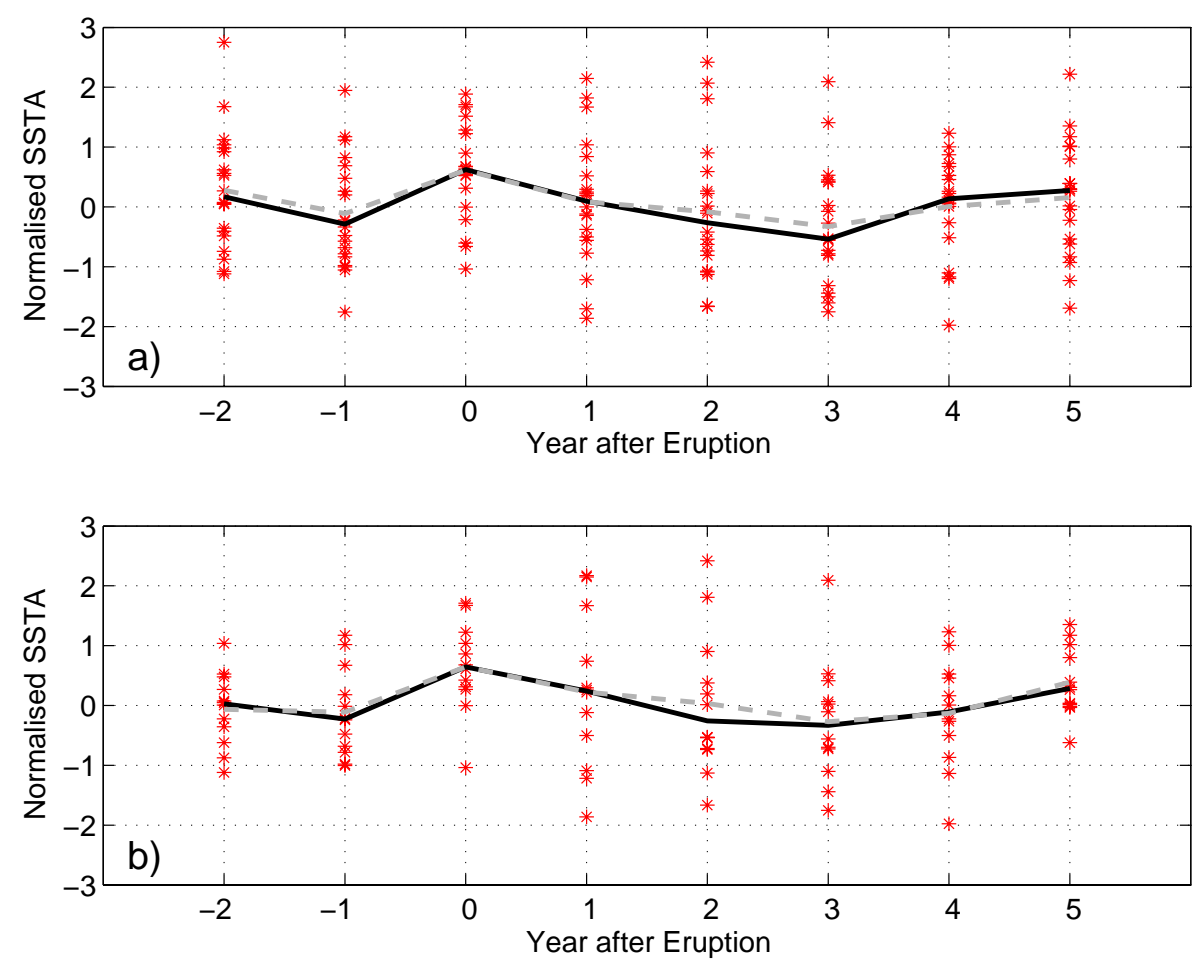

Fig. 11. Composites of the UEP around years in which explosive volcanism occurred where volcanic events are defined using the (a) IVI and (b) ICI indices. The solid black line indicates the composite mean while the gray dashed line indicates the composite median.

Consistent with the thermostat mechanism, past studies have suggested that explosive volcanic events (which reduce radiative forcing) tend to lead to a higher probability of El Niño type events in the years following the eruption (Adams et al., 2003). Here we reassess these findings over the period 1650-1977 using the UEP, the ice-core volcanic index (IVI) of Gao et al. (2008) and the ice-core index (ICI) of volcanic events by Crowley et al. (2008). To this end, both the IVI and ICI data were then discretized into a binary format where 1's (0's) indicate whether a volcanic event occurred (did not occur) in the given year. A subset of the UEP data was then made which incorporated an eight year window of data from the UEP (consisting of the 2-yrs prior to the event, the event year and the 5-yrs following the event) for each of the recorded volcanic events. Visual analysis of these data subsets reveals two distinct features, (i) a shift in the data towards more El Niño like conditions in the year of the volcanic eruption, and (ii) a shift in the data towards more $\mathrm{La}$ Niña like conditions approximately 2-3 years after the volcanic eruption (Fig. 11). Both of these features are consistent with Adams et al. (2003) and not inconsistent with the results expected from the thermostat mechanism of Clement et al. (1996).

We now specifically test the null hypothesis: volcanic forcing has no effect on the mean state, median or probability of ENSO in the years during or surrounding the volcanic event. We find that the distribution of the UEP shifts toward more El
Niño-like state the year both the IVI or the ICI mark an eruption event. Two statistical tests support the significance of the shifts: the t-test (which shows that the change in mean state is significant above the 95\% level), and the Mann-Whitney U-test (which shows that the change in the median is statically significant above the 95\% level) (Fig. 11). However, while the shift towards a La Niña like mean state $2-3$ years after the volcanic event is apparent in both data subsets, the shift in mean state and the median in either data subset is not statistically significant.

Using a half standard deviation threshold to define discrete ENSO events we find that probability of an El Niño event occurring in a given year goes from $26 \%$, when volcanic events are not taken into account, to $58 \%$ in the year of a volcanic event using the IVI defined events and to $70 \%$ in the year of a volcanic event using the ICI defined events. Assessing the statistical significance of these changes in probability using a Monte-Carlo type approach, we find that the IVI (ICI) defined shifts are significant above the 99\% (95\%) level. The probability of a La Niña event in any given year goes from $25 \%$, when volcanic events are not taken into account, to $55 \%$ (50\%) 3-years after a volcanic event using the IVI (ICI) defined events. Again, using the Mont-Carlo type approach we find that this IVI (ICI) related shift in probability is significant above the $95 \%(80 \%)$ level. Thus, this result supports the earlier work of Adams et al. (2003) and suggests that changes in radiative forcing due to volcanic 
eruptions act to significantly alter the mean state and median of ENSO while also significantly altering the probability of ENSO events occurring. Hence, the null hypothesis can be rejected with some degree of confidence.

\section{Discussion and conclusions}

In this manuscript we defined a new proxy of ENSO variability covering the last $31 / 2$ centuries, titled the "Unified ENSO Proxy" (UEP). The UEP uses a PCA to combine the joint signal in the 10 selected, previously defined, reconstructions of ENSO (Dunbar et al., 1994; Stahle et al., 1998; Cook, 2000; Mann et al., 2000; Evans et al., 2001, 2002; Cobb et al., 2003; Cook et al., 2008; Braganza et al., 2009). This results in a robust ENSO index which displays an enhanced correspondence with observations during the last century and with historical chronologies of ENSO over the entire period. We note here that each of the individual ENSO reconstructions used as input for this manuscript could be affected by the changing strength of ENSO teleconnections, dating uncertainties, biological biases, regional climatic factors and other non-ENSO related large scale climatic modes. As such, so could the UEP. However, each of the input reconstructions used that was derived from multiple site proxies were processed by the generating authors in order to extract the ENSO signal away from this unrelated noise (Stahle et al., 1998; Cook, 2000; Mann et al., 2000; Evans et al., 2001, 2002; Braganza et al., 2009). Additionally, here we carry out a PCA on these pre-processed ENSO reconstructions, derived from a global proxy network, which acts to further reduce the potential errors due to site specific ENSO reconstruction biases.

Upon analysis of the UEP, the feature that stands out most is the increase in variance through time. This feature is well represented by the dominant mode of running mean variance of the 10 original input proxies, meaning that it is a feature in the majority of the input proxies. Further to this, it appears consistent with historic chronologies of ENSO and three separate un-utilized proxies of ENSO variability. As to the cause of this increase in variance, it is still an open question. Interestingly though, this increase in ENSO variance roughly coincides with an increase in Western Pacific warm pool temperature (Newton et al., 2006). Consistent with the ENSO variance changes displayed by the UEP, the increasing temperature of the Western Pacific warm pool should lead to enhanced ENSO variance, provided the subsurface ocean remains at the same temperature (Sun, 2000). It was also recently reported that the Inter-tropical Convergence Zone (ITCZ) migrated northward between the year 1700 and 1850 (Sachs et al., 2009). The effect the northward migration of the ITCZ would have on the variance of ENSO is unclear at this stage. For instance, numerous studies conjecture that the northward (southward) migration of the ITCZ should lead to decreased (increased) ENSO variance (Haug et al., 2001; Koutavas and Lynch-Stieglitz, 2004). However, model evi- dence from the perpetual month experiments of Tziperman et al. (1997) (where the Zebiak and Cane (1987) anomaly models background annual cycle winds, ocean currents and the associated ITCZ position are held fixed) is inconclusive as it indicates that ENSO is extremely damped when the ITCZ is both at its northern and southern most extremes in September and February respectively. To further explore the role of Western Pacific warm pool temperature changes and the northward migration of the ITCZ on the variance of ENSO, future work will investigate the associated changes in zonal convection, flow divergence, thermal damping, Ekman pumping and thermocline feedbacks by computing the seasonally varying BJ index (Jin et al., 2006) of climate models subject to modified WPWP temperature and ITCZ latitude.

Using the UEP we also analyzed several topical issues in the ENSO literature, the occurrence of multi-year El Niño events, multi-decadal variability and the effects of solar and volcanic forcing. In regards to multi-year or prolonged ENSO events, a study by Trenberth and Hoar (1996) estimated the prolonged El Niño event of the early 1990s, which persisted for 5-yrs by some measures, would only occur once in approximately 1500-3000-yrs. Using the newly defined ENSO proxy, the UEP, and a half standard deviation threshold to classify ENSO events, we find that while the prolonged El Niño event of the early 1990s was unusual, it is neither a one off and or the longest El Niño event on record. Prolonged ENSO events have occurred at least several times over the last $3 \frac{1}{2}$ centuries, with El Niño events that persist for 3 or more years generally occurring 2-3 times per century.

Looking at the multi-decadal variability of the UEP, we find that (i) the UEP displays multi-decadal variability that is consistent with the 20th century variability of the PDO and IPO, (ii) significant decadal variability has persisted throughout the last 350-yrs, and (iii) the phase of this multidecadal variability does not appear to influence the variance of ENSO. Assessing whether changes solar forcing affect ENSO mean state and variance of the last 350-yrs we find, no conclusive support for a relationship on multi-decadal time scales in contrast to the conclusions from the idealized modeling study of Emile-Geay et al. (2007), and no conclusive support for changes in the mean state (the thermostat mechanism) in contrast to the study of Mann et al. (2005). However, we find that volcanic forcing can induce a statistically significant change in the mean state and median of ENSO in the years following the eruption. Further to this, we find that volcanic events can significantly alter the probability of El Niño (La Niña) events occurring in the year of, and three years after, the volcanic event, consistent with the earlier study of Adams et al. (2003). A forthcoming study will further elucidate how external volcanic forcing changes the timing and characteristics of ENSO events. 
Acknowledgements. This work is supported by NOAA's CCDD program under grant number NA08OARH320910. The UEP and its low-pass filtered decadal component is made available on the World Data Center (WDC) for paleoclimatology and the Asia-Pacific Data Research Center (APDRC).

\section{Edited by: B. L. Otto-Bliesner}

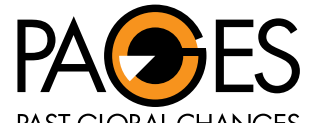

The publication of this article was sponsored by PAGES.

\section{References}

Adams, J., Mann, M. E., and Ammann, C. M.: Proxy evidence for an El Niño-like response to volcanic forcing, Nature, 426, 274278, 2003.

Biondi, F., Gershunov, A., and Cayan, D. R.: North Pacific Decadal Climate Variability since 1661, J. Climate, 14, 5-10, 2001.

Boës, X. and Fagel, N.: Relationships between southern Chilean varved lake sediments, precipitation and ENSO for the last 600 years, J. Paleolimnol., 39, 237-252, doi:10.1007/s10933-0079119-9, 2008

Braganza, K., Gergis, J. L., Power, S. B., Risbey, J. S., and Fowler, A. M.: A multiproxy index of the El Niño-Southern Oscillation, A.D. 1525-1982, J. Geophys. Res., 114, D05106, doi:10.1029/2008JD010896, 2009.

Bunge, L. and Clarke, A. J.: A verified estimation of the El Niño index NINO3.4 since 1877, J. Climate, 22, 3979-3992, 2009.

Cane, M., Clement, A. C., Kaplan, A., Kushnir, Y., Pozdnyakov, D., Seager, R., Zebiak, S. E., and Murtugudde, R.: Twentiethcentury sea surface temperature trends, Science, 275, 957-960, 1997.

Chan, J.: Tropical cyclone activity in the northwest Pacific in relation to the El Niño/Southern Oscillation phenomenon, Mon. Weather Rev., 113, 599-606, 1985.

Clement, A., Seager, R., Cane, M. A., and Zebiak, S. E.: An ocean dynamical thermostat, J. Climate, 9, 2190-2196, 1996.

Cobb, K., Charles, C. D., Cheng, H., and Edwards, R. L.: El NiñoSouthern Oscillation and tropical Pacific climate during the last millenium, Nature, 424, 271-276, 2003.

Conroy, J. L., Restrepo, A., Overpeck, J. T., Steinitz-Kannan, M., Cole, J. E., Bush, M. B., and Colinvaux, P. A.: Unprecedented recent warming of surface temperatures in the eastern tropical Pacific Ocean, Nat. Geosci., 2, 46-50, doi:10.1038/NGEO390, 2009.

Cook, E.: Niño 3 Index Reconstruction, in: International Tree-Ring Data Bank, IGBP PAGES/World Data Center-A for Paleoclimatology Data Contribution Series, 2000.

Cook, E. R., D’Arrigo, R. D., and Anchukaitis, K. J.: ENSO reconstructions from long tree-ring chronologies: Unifying the differences, in: Talk presented at a special workshop on Reconciling ENSO Chronologies for the Past 500 Years, held in Moorea, French Polynesia on 2-3 April 2008, 2008.

Crowley, T. J., Zielinski, G., Vinther, B., Udisti, R., Kreutz, K., Cole-Dai, J., and Castellano, E.: Volcanism and the Little Ice Age, PAGES news, 16, 22-23, 2008.
D'Arrigo, R., Villalba, R., and Wiles, G.: Tree-ring estimates of Pacific Decadal Climate Variability, Clim. Dynam., 18, 219-224, 2001.

Davis, R.: Predictability of Sea Surface Temperature and Sea Level Pressure anomalies over the North Pacific Ocean, J. Phys. Oceanogr., 6, 249-266, 1976.

Dunbar, R., Wellington, G. M., Colgan, M. W., and Glynn, P. W.: Eastern Pacific sea surface temperature since 1600 A.D.: The $\delta^{18} \mathrm{O}$ record of climate variability in Galápagos corals, Paleoceanography, 9, 291-315, 1994.

Emile-Geay, J., Cane, M. A., Seager, R., Kaplan, A., and Almasi, P.: El Niño as a mediator of the solar influence on climate, Paleoceanography, 22, PA3210, doi:10.1029/2006PA001304, 2007.

Evans, M., Kaplan, A., Cane, M. A., and Villalba, R.: Interhemispheric Climate Linkages, chap. Globality and optimality in climate field reconstructions from proxy data, Cambridge University Press, 53-72, 2001.

Evans, M., Kaplan, A., and Cane, M. A.: Pacific sea surface temperature field reconstruction from coral $\delta^{18} \mathrm{O}$ data using reduced space objective analysis, Paleoceanography, 17, 1007, doi:10.1029/2000PA000590, 2002.

Federov, A. and Philander, S. G.: Is El Niño changing?, Science, 288, 1997-2002, 2000

Folland, C. K., Renwick, J. A., Salinger, M. J., and Mullan, A. B. Relative influences of the Interdecadal Pacific Oscillation and ENSO on the South Pacific Convergence Zone, Geophys. Res. Lett., 29, 1643, doi:10.1029/2001GL014201, 2002.

Gao, C., Robock, A., and Ammann, C.: Volcanic forcing of climate over the past 1500 years: An improved ice core-based index for climate models, J. Geophys. Res., 113, D23111, doi:10.1029/2008JD010239, 2008

Garcia-Herrera, R., Diaz, H. F., Garcia, R. R., Prieto, M. R., Barriopedro, D., Moyano, R., and Hernández, E.: A chronology of El Niño events from primary documentary sources in Northern Peru, J. Climate, 21, 1948-1962, doi:10.1175/2007JCLI1830.1, 2008.

Gergis, J. and Fowler, A. M.: A history of ENSO events since A.D. 1525: Implications for future climate change, Climatic Change, 92, 343-387, doi:10.1007/s10584-008-9476-z, 2009.

Haug, G. H., Hughen, K. A., Sigman, D. M., Peterson, L. C., and Rohl, U.: Migration of the Intertropical Convergence Zone through the Holocene, Science, 293, 1304-1308, 2001.

Hendy, E., Gagan, M. K., and Lough, J. M.: Chronological control of coral records using luminescent lines and evidence for non-stationary ENSO teleconnections in northeast Australia, The Holocene, 13, 187-199, 2003.

Jin, F., Kim, S., and Bejarano, L.: A coupled-staibility index for ENSO, Geophys. Res. Lett., 33, L23708, doi:10.1029/2006GL027221, 2006.

Kaplan, A., Cane, M., Kushnir, Y., Clement, A., Blumenthal, M., and Rajagopalan, B.: Analyses of global sea surface temperature 1856-1991, J. Geophys. Res., 103, 567-589, 1998.

Kessler, W. and McPhaden, M.: The 1991-93 El Niño in the Central Pacific, Deep-Sea Res. Pt. II, 42, 295-333, 1995.

Kirtman, B. and Schopf, P.: Decadal variability in ENSO predictability and prediction, J. Climate, 11, 2804-2822, 1998.

Koutavas, A. and Lynch-Stieglitz, J.: The Hadley Circulation: Present Past and Future, chap. Variability of the marine ITCZ over the eastern Pacific during the past 30,000 years, Kluwer 
Academic Publishers, Boston, 347-369, 2004.

Latif, M., Kleeman, R., and Eckert, C.: Greenhouse Warming, Decadal Variability, or El Niño? An attempt to understand the anomalous 1990s, J. Climate, 10, 2221-2239, 1997.

Lean, J., Beer, J., and Bradley, R.: Reconstruction of Solar Irradiance since 1610: Implications for Climate Change, Geophys. Res. Lett., 22, 3195-3198, 1995.

Mann, M., Bradley, R. S., and Hughes, M. K.: Multiscale Variability and Global and Regional Impacts, chap. Long-term variability in the El Niño-Southern Oscillation and asscoiated teleconnections, Cambridge University Press, 357-412, 2000.

Mann, M., Cane, M. A., Zebiak, S. E., and Clement, A.: Volcanic and Solar Forcing of the Tropical Pacific over the Past 1000 Years, J. Climate, 18, 447-456, 2005.

Mantua, N., Hare, S. R., Zhang, Y., M.Wallace, J., and Francis, R. C.: A Pacific interdecadal climate oscillation with impacts on salmon production, B. Am. Meteorol. Soc., 78, 1069-1079, 1997.

Meehl, G. A., Arblaster, J. M., Matthes, K., Sassi, F., and van Loon, H.: Amplifying the Pacific Climate System response to a small 11-year Solar Cycle forcing, Science, 325, 1114-1118, doi:10.1026/science.1172872, 2009.

Merryfield, W. J.: Changes to ENSO under CO2 doubling in a multimodel ensemble, J. Climate, 19, 4009-4027, 2006.

Newton, A., Thunell, R., and Stott, L.: Climate and hydrographic variability in the Indo-Pacific Warm Pool during the last millenium, Geophys. Res. Lett., 33, L19710, doi:10.1029/2006GL027234, 2006.

Nicholls, N.: Predictability of interannual variations of Australian seasonal tropical cyclone activity, Mon. Weather Rev., 113, 1144-1149, 1985.

Ortlieb, L.: Multiscale Variability and Global and Regional Impacts, chap. The documented historical record of El Niño events in Peru: An update of the Quinn Record (Sixteenth through Nineteenth Centuries), Cambridge University Press, 207-295, 2000.

Power, S. and Smith, I. N.: Weakening of the Walker Circulation and apparent dominance of El Niño both reach record levels, but has ENSO really changed?, Geophys. Res. Lett., 34, 18702, doi:10.1029/2007GL030854, 2007.

Power, S., Casey, T., Folland, C., Colman, A., and Mehta, V.: Interdecadal modulation of the impact of ENSO on Australia, Clim. Dynam., 15, 319-324, 1999.

Quinn, W. and Neal, V. T.: Climate since A.D. 1500, chap. The historical record of El Niño events, Routledge, 623-648, 1992.

Rayner, N., Parker, D., Horton, E., Folland, C., Alexander, L., Rowell, D., Kent, E., and Kaplan, A.: Global analyses of sea surface temperature, sea ice, and night marine air temperature since the late nineteenth century, J. Geophys. Res., 108, 4407, doi:10.1029/2002JD002670, 2003.
Rodgers, K., Friedrichs, P., and Latif, M.: Tropical Pacific Decadal Variability and Its Relation to Decadal Modulations of ENSO, J. Climate, 17, 3761-3774, 2004.

Ropelewski, C. F. and Halpert, M. S.: Global and Regional precipitation patterns associated with the El Niño/Southern Oscillation, Mon. Weather Rev., 115, 1606-1626, 1987.

Sachs, J. P., Sachse, D., Smittenberg, R. H., Zhang, Z., Battisti, D. S., and Golubic, S.: Southward movement of the Pacific intertropical convergence zone AD 1400-1850, Nat. Geosci., 2, 519-525, doi:10.1038/NGEO554, 2009.

Schopf, P. S. and Burgman, R. J.: A simple mechanism for ENSO residuals and asymmetry, J. Climate, 19, 3167-3179, 2006.

Stahle, D., D'Arrigo, R. D., Krusic, P. J., Cleaveland, M. K., Cook, E. R., Allan, R. J., Cole, J. E., Dunbar, R. D., Therrell, M. D., Gay, D. A., Moore, M. D., Stokes, M. A., Burns, B. T., Villanueva-Diaz, J., and Thompson, L. G.: Experimental dendroclimatic reconstruction of the Southern Oscillation, B. Am. Meteorol. Soc., 79, 2137-2152, 1998.

Sun, D.-Z.: Multiscale Variability and Global and Regional Impacts, chap. Global Climate Change and El Niño: A theoretical framework, Cambridge University Press, 443-463, 2000.

Theiler, J., Eubank, S., Longtin, A., Galdrikian, B., and Farmer, J. D.: Testing for nonlinearity in time series: the method of surrogate data, PhysicaD, 58, 77-94, 1992.

Timmermann, A.: Detecting the nonstationary response of ENSO to Greenhouse Warming, J. Atmos. Sci., 56, 2313-2325, 1999.

Trenberth, K. and Hoar, T. J.: The 1990-1995 El Niño-Southern Oscillation event: Longest on record, Geophys. Res. Lett., 23 , 57-60, 1996.

Trenberth, K. and Hurrell, J. W.: Decadal atmosphere-ocean variations in the Pacific, Clim. Dynam., 9, 303-319, 1994.

Trenberth, K. E. and Stepaniak, D. P.: Indices of El Niño Evolution, J. Climate, 14, 1697-1701, 2001.

Tziperman, E., Zebiak, S. E., and Cane, M. A.: Mechanisms of Seasonal - ENSO interaction, J. Atmos. Sci., 54, 61-71, 1997.

van Oldenborgh, G. J., Philip, S. Y., and Collins, M.: El Niño in a changing climate: a multi-model study, Ocean Sci., 1, 81-95, 2005 , http://www.ocean-sci.net/1/81/2005/.

von Storch, H. and Zwiers, F. W.: Statistical Analysis in Climate Research, Cambridge University Press, 2000.

Yeh, S.-W. and Kirtman, B. P.: Pacific Decadal Variability and ENSO amplitude modulation, Geophys. Res. Lett., 32, L05703, doi:10.1029/2004GL02173, 2005.

Zebiak, S. E. and Cane, M. A.: A model El Niño-Southern Oscillation, Mon. Weather Rev., 115, 2262-2278, 1987.

Zhang, Y., Wallace, J. M., and Battisti, D. S.: ENSO-like Interdecadal Variability: 1900-93, J. Climate, 10, 1004-1020, 1997. 